\title{
Innovation and Practice of Digital Resource Services in University Libraries under the Background of COVID-19 Pandemic
}

\author{
Chunyu Wang ${ }^{1, *}$ \\ ${ }^{1}$ The Library of Wuhan University of Technology, Wuhan, Hubei 430070, China \\ *Corresponding author. Email: wangchy@whut.edu.cn
}

\begin{abstract}
Regarding the digital resource services of university libraries under the COVID-19 pandemic as the research object, this paper aims to explore the digital resource service methods of university libraries under the circumstance of public health emergency and improve the service of university digital resources. Based on the practical research and theoretical analysis, this paper starts from the necessity and availability of innovating university library digital resource services, and discusses the innovation measures under the COVID-19 pandemic, including expanding the off-campus access to library digital resource, integrating and pushing digital resources, establishing mutual QQ groups for document delivery, and providing electronic teaching textbooks. These measures can provide some references for innovating digital resource services of university libraries when it comes to public health emergency.
\end{abstract}

Keywords: The COVID-19 pandemic, University libraries, Digital resources, Service innovation

\section{INTRODUCTION}

The COVID-19 pandemic, breaking out in Wuhan at the beginning of 2020, has become the major public health emergency in China. In order to contain the outbreak in campus and guarantee students' safety and health, the Ministry of Education issued The Notice of Postponing Schooling in the Spring of 2020 on January 27th, 2020. Meanwhile, various schools are required to launch online classes[1], fully using information technology, resource and platforms to arrange related online learning and teaching. All university libraries issued the notice of closing temporarily or postponing the schooling one after another. Physical libraries have closed and university libraries are facing the great challenge on service. With the demand of current and future users, libraries should have new service concepts, models and abilities. Specifically, they should establish the service concept oriented with users [2] to construct service model and ability under the new circumstance [3]. University teachers and students highly rely on the Internet and library digital resources for their teaching and research under the COVID-19 pandemic. Due to the need of preparing research, course teaching and graduate paper, it is of great significance for university libraries to offer digital resource services and more convenient methods of sharing these resources. The library of Wuhan University of Technology (WHUT) has launched a series of innovation measures on digital resource services, providing literature resources for the teaching and scientific research of teachers and students.

\section{EXPANDING THE OFF-CAMPUS ACCESS TO LIBRARY DIGITAL RESOURCES}

\subsection{Overload of VPN in Universities}

Outside campus, teachers and students can visit digital resources via university VPN. Since the COVID-19 pandemic, VPN has appeared to be stuck due to the increasing online learning. Even though network information center has immediately ramped up the capacity of VPN system, the increasing user demand can't be satisfied. Some teachers and students can't use VPN at times. During the pandemic, it is more difficult for readers to visit library digital resource via VPN. So, in order to make it convenient for teachers and students, libraries have connected with university network centers to adjust the visit access to part database. CARSI can serve as a method to visit these databases.

\subsection{Providing Remote Access to Digital Resources of Library based on Shibboleth from the Platform of CARSI}

In order to make it convenient for teachers and students, libraries and network centers have applied to visit part database via CARSI. CARSI (CERNET Authentication and Resource Sharing Infrastructure), an open course program 
based on Shibboleth, was established by the computer center of Peking University (PKU) in December, 2008. Based on the campus unified user management and identification system which has been founded within most domestic universities, it provides cross-industry identification and resource sharing for China's universities and research institutions. With the help of CARSI, readers can login with their usernames of the campus network to access part digital resource, without using the IP of campus website. Then the overloaded campus server due to lots of users connecting VPN at the same time can be avoided, and readers can enjoy the fast and valid visit.

On February 20th, 2020, WHUT finished debugging the IDP identification server and applied to PKU for being online. Since February 23rd, 16 library databases have been debugged and realized the visit by CARSI identification including CNKI, Web of Science (SCI, SSCI, CPCI), Elsevier ScienceDirect, IEEE/IET Electronic Library and SpringerLink. Other databases will be consecutively debugged and online. Meanwhile, libraries will timely deliver the notice of visiting part databases via CARSI and related using guidance on campus network and We-chat official account. On the first day, the number of users visiting library database via CARSI reached 2000. By April 1 st, the visiting number reached 112,268.

\section{INTEGRATING AND PUSHING DIGITAL RESOURCES}

\subsection{Integrating and Pushing Digital Resource Collections}

During the COVID-19 pandemic, collections of academic resource are the fundamental guarantee for teachers' and students' scientific research. Before this outbreak, the main medium of pushing library digital resource was that librarians delivered a one-hour offline lecture every week. After the pandemic, libraries rewrote the guidelines for subscribed database according to various disciplines, and set special column in We-chat official account to push notification for readers. And libraries have constantly recommended 15 databases and their platform introductions and guidelines, including CNKI, core collections of Web of Science, Elsevier ScienceDirect, IEEE, SAE International, NoteExpress, World eBook Library and ProQuest Research Library.

Long-term home quarantine is needed during the coronavirus, which may make people sensitive and anxious about interpersonal relationship. But some researches have showed that reading can reduce mental pressure and prevent mental diseases. Libraries selected classics of literature, philosophy and ethics from Chaoxing e-book database, and push them at the special column of library We-chat account "Pleasure Reading". Such recommendations for special classics reading can give play to the function of "cultivating people with literature”. Ideological and psychological counselling can help teachers and students enhance their mental immunity, reduce the disturbance and hurt on their mental health, and promote their abilities to prevent and control the "virus".

\subsection{Integrating and Pushing Free Digital Resources}

Besides integrating and pushing existing digital resources, libraries have also delivered free digital resources for readers during the COVID-19 pandemic. During the pandemic, the free digital resources mainly include: The first one is free within limited time. In order to combat the pandemic, lots of database producers, publishers and Internet companies have opened their academic resources for free in limited time. The second one is trial databases. During this special time, some databases have opened trial databases for university libraries. The third one is to acquire digital resources in an open way. Because the related information is too fragment, readers can have access to digital resources from the library We-chat account that can expand the species and ranges of current digital resources. There are 30 Chinese and foreign digital resources including Baidu Wenku, IGI Global, NoteExpress and Annual Reviews. In addition, libraries have connected some trial open databases, like academic database of coronavirus on PreQuest, A\&HCI (Arts and Humanities Citation Index), ESCI (Emerging Sources Citation Index) and database backtracking of SCIE/SSCI. Integration and push of free digital resources can help teachers and students get more abundant digital resources.

\subsection{Integration and Pushing Free Online Training Course}

During the COVID-19 pandemic, some database providers have launched series of lectures to introduce the searching methods of academic journals, books and databases, and the writing and submission skills of academic papers. These free online courses are too fragmented on the Internet, so libraries searched the online training courses of database producers and delivered them to readers via We-chat account and QQ groups in various stages. For example, 22 WOS online lectures of libraries for scientific researchers, 3 live public classes of EBSCO, 6 regular courses of IEEEXplore MOOC and 6 online courses of Springer Nature.

What's more, some database providers irregularly held online seminars, which were integrated by the library. And some related seminars were selected to push on the We-chat account and QQ groups of corresponding departments. For instance, Elsevier held the online seminar "Advanced Technology and Career Planning of Scientists" on March 21st, which mentioned that optimizing materials can help reshape batteries. Then the library pushed this seminar on We-chat account and QQ group of the Department of Materials in advance.

In addition, it pushed the Lecture Hall of Scientific Research Qualities in Chinese Academy of Sciences on the We-chat 
account. This is a platform for training scientific research information qualities, and the National Science and Technology Library in Chinese Academy of Sciences is the leading part. It serves postgraduates and scientific researchers, and helps acquiring, managing and applying scientific research information. The lecture topics include "Scopus opens the new horizon in scientific research for you", "Web of Science, one step ahead" and "ScienceDirect makes scientific research more efficient".

\section{ESTABLISHING MUTUAL QQ GROUPS FOR DOCUMENT DELIVERY}

\subsection{Establishing Mutual QQ Groups to Deliver Documents}

The service method of document delivery can help library information and related institutions meet the timely need of users on the Internet. And it is also the extension and expansion of traditional interlibrary loan services under network environment. Currently, CALIS, CASHL and NSTL are the main document delivery service systems that provide literature guarantee for national university teaching and scientific research. At usual, readers can have access to document delivery through the corresponding gateway on the homepage of libraries. But with the outbreak of COVID-19, readers have gone to different places across the nation, covering prosperous cities and remote areas with less developed transportation. For the latter, maybe they don't have computers at home, so it is hard for them to visit library resources via VPN. In addition, VPN seems to be stuck due to a large amount of online learning. In order to help readers faster acquire the library digital resources and meet their need of document resources when it is not convenient for them to use campus network, libraries have established mutual QQ groups to deliver documents.

\subsection{The Service Methods of Mutual QQ Groups for Document Delivery}

During the COVID-19 pandemic, as long as teachers and students need to acquire some electronic documents, they can ask for help even if these documents are available in their campus databases. Help seekers can post the title, DOI, detailed information or link of the paper in mutual groups for document delivery. Librarians in these groups will respond to the help from 8:30 to 22:30 every day, and timely email the results to help seekers.

Such service method enjoys great popularity among teachers and students. So far, more than 2800 teachers and students have accepted the service. From February 1st to March 31st, 2020, mutual groups received 2727 literature help, among which there were 615 for Chinese literature and 2112 for foreign literature. And librarians successfully emailed 2505 original literature. The guarantee rate reached $91.75 \%$.

\section{PROVIDING ELECTRONIC TEACHING TEXTBOOKS}

Under the COVID-19 pandemic, it is a must to have online classes so that electronic textbooks and references are in great need. S. R. Ranganathan, an outstanding library scientist around the world, put forward famous "five principles" in 1931, which have been regarded as the general principle of library industry. The fourth is to "save readers' time” [5]. Modern library pays attention to the targeted service [6]. During this pandemic, those university libraries that can provide targeted service of electronic textbooks and references are based on the existing e-reserve system (platform). University library working commission made researches with libraries of 39 original "985" universities (the most famous universities in China), and only 9 libraries have their textbook and reference system. And WHUT library isn't on the list. So, in face of the urgent need for electronic textbooks, libraries immediately made Guidance for Acquiring Electronic Textbooks to help teachers and students save time finding electronic textbooks and provide targeted services for them.

In this spring semester of 2020, undergraduates in WHUT have 3,695 courses in total. From February 6th to 29th, library received eight groups of undergraduate course information from the Office of Academic Affairs and various departments, reaching over 3,000 messages of course and textbooks. After checking all of them and removing the repeated, the total number of textbooks is 2503 . Based on the experience of other universities in acquiring electronic textbooks and existing resources, WHUT library classified it into five kinds: one, existing learning platform of Xuexitong; two, existing reading platform of Duxiu; three, free reading within the limited time on network platforms of the publishing house; four, specific publishers for WHUT; five, part textbooks can be compiled by course instructors. According to these methods, the library searched and arranged these 2503 textbooks and compiled Guidance for Acquiring Electronic Textbooks. The third edition of this guide was finished on January 29th, 2020, covering 2,052 electronic textbooks. Compared with the total need of 2,503, the guarantee rate reached $81.98 \%$.

\section{CONCLUSION}

With the outbreak and spreading of COVID-19, physical libraries in universities were closed. During this period, how can libraries provide digital resource services for teachers and students having online classes, and guarantee the literature resources for their scientific research and teaching? The library of WHUT has launched a series of library digital resource services innovation practice based on the practical conditions, forming its own characteristics and providing certain reference for other libraries. When it comes to similar major public health incidents like this pandemic in the future, university libraries can make this experience as the reference to deal with digital resource services. In order to better serve scientific research and teaching, libraries can 
expand the method of visiting library resources outside campus, integrate the collections and free social resources, and focus on the establishment of the e-reserve system (platform).

\section{ACKNOWLEDGMENT}

This work was supported by Fundamental Research Funds for the Central Universities (WUT: 2020IVB072).

\section{REFERENCES}

[1] Wei Dawei, Liao Yongxia, Ke Ping, Discussion on library emergency services during major public safety emergencies, Library Journal 39(1) (2020) 4-18. DOI: https://doi.org/10.13663/j.cnki.lj.2020.03.001

[2] Chu Jingli, The strategic transition of library services in the era of digitalization and networking, Library and Information 40(1) (2017) 98-104. DOI:

https://doi.org/10.11968/tsyqb.1003-6938.2017014
[3] Yuan Qing, Shi Liang, Chen Meng, Construction of university libraries service ability driven by "Double First-Class": A case study of Huazhong University of Science and Technology, Library and Information Service 63(1) (2019) 118-124. DOI: https://doi.org/10.13266/j.issn.0252-3116.2019.01.017

[4] Li Junkai, The study on the patterns and trends of document delivery service in China from the cases of CASHL and NSTL, Journal of Academic Libraries 22(6) (2004) 33-37. DOI: https://doi.org/10.3969/j.issn.1002-1027.2004.06.009

[5] Ke Ping, Study of the theory of library services, Journal of Academic Libraries 24(1) (2006) 38-44. DOI: https://doi.org/10.3969/j.issn.1002-1027.2006.01.009

[6] Yang Yanhong, Hao Dan, Wang Yanxi, Precision service method and application practice of library in university transformation period: A case study of Qiongtai Normal University, Library and Information Service 62(11) (2018) 72-78. DOI: https://doi.org/10.13266/j.issn.0252-3116.2018.11.008 